Review

\title{
Are Mobile Live Animal Programs Educationally Beneficial? A Critical Assessment of the Human Learning Component Underlying Traveling Animal Exhibits
}

\author{
Kathryn Sussman
}

Zoocheck Inc., 788 1⁄2 O'Connor Drive, Toronto, ON M4B 2S6, Canada; kjsussman@gmail.com Tel.: 001416 875-4212

Simple Summary: This article addresses the problem of negative education that results from participating in Mobile Live Animal Programs (MLAP). Its aim is to determine what constitutes both positive and negative education and to examine how and if these types of learning can be measured in regard to MLAPs. The conclusion reached is that there is no evidence of affective learning that results in increased conservation efforts from participating in MLAPs, and, furthermore, there is an accumulation of learning that occurs in the form of a negative emotional and intellectual perception of non-human species. Given the accumulation of negative educational value that outweighs any cognitive acquisition of facts regarding the animals being presented, the conclusion reached is that it is not recommended, based on their purported educational claims, that MLAPs be given special consideration when it comes to laws restricting or prohibiting animal use within municipal or provincial/state boundaries. This information can be used to help shape future legislation that works to protect non-human animals, and contributes to our perceptions of non-human animals as persons rather than commodities.

\begin{abstract}
This paper assesses whether there is intrinsic positive educational value in travelling animal presentations and exhibits, referred to here as Mobile Live Animal Programs (MLAPs). Given that educational claims serve as the basis for allowing MLAPs to operate in many jurisdictions throughout Canada and the United States, it is essential to examine whether these purported claims are valid. This study takes a twofold approach of examining first, what constitutes an MLAP and how such programs are situated within the larger context of animal observation and tourism, and second, what constitutes both positive and negative education, and how such learning can empirically be measured in these settings. This approach provokes the ethical question of whether or not MLAPs should be allowed to operate given the high price paid not only by the individual animals used, but also to our psychological, emotional, and intellectual relationship with other species when we use non-human animals for our own knowledge, pleasure or comfort. The paper concludes that we must consider that the pervasive problem of negative education, that using displaced captive wild animals as learning tools that highlights human control over them, their objectification and their exploitation, is not justified by the purported positive educational claims of MLAPs.
\end{abstract}

Keywords: zoo; mobile zoo; mobile animal exhibits; animal display; mobile live animal programs; negative education 


\section{Introduction}

Mobile Live Animal Programs (MLAPs) are businesses that operate by transporting nonhuman animals (heretofore referred to as animals) to various locations such as private in-home birthday parties, nursing homes, retirement facilities, schools, daycare centers, religious institutions such as churches, corporate functions and community-events, i.e., consumer and trade shows. The animals are confined and transported in ad-hoc or purpose-built containers including trailers for larger hoofed animals like donkeys, zebras and camels, and wooden crates, kennel carriers and rubber tubs or other such similar containers for smaller species. At these various locations, the animals are used as displays in temporary exhibits and/or for live animal presentations. Many of these displays are interactive, allowing for the frequent touching, petting and handling of the animals by the public.

An MLAP may be privately-owned by an exotic animal keeper or collector who conducts live animal presentations locally or further afield, or it can be a publically owned operation, such as a major urban zoo that conducts an offsite animal outreach program. As well as being both for-profit and non-profit, what all MLAPs have in common is that they all provide a service - the animal presentation or exhibit - for a fee. MLAPs can be distinguished from travelling circuses in that they generally do not force the animals to perform circus-like tricks for human amusement.

MLAPs resemble first generation zoo displays of the $19^{\text {th }}$ century, when zoos existed almost exclusively as sites of recreation and leisure for human entertainment and pleasure. At this time, zoos exhibited wild animals in cages or concrete, barren enclosures in rigidly controlling environments emphasizing their lack of freedom [1], reflecting the conspicuous wealth and 'reach' of the relevant empires and kingdoms [2]. While well-run progressive modern day zoos focus some attention on research and conservation and make efforts to present animals in naturalistic displays - exhibits that have natural vegetation and landscaping, where animals are able to practice natural behaviours, can escape excess heat or cold, and often are provided with items that stimulate their interest, referred to as enrichment [1] - these goals and animal welfare standards are not present, nor achievable, in the case of MLAPs. In contrast to most permanent zoo exhibits, where there is an attempt to replicate some aspects of the natural habitat of the animals, MLAPs involve keeping animals in sterile situations that are entirely removed from any authentic ecological contexts. The animals, furthermore, are presented in highly artificial, often stressful conditions where they are utilized as objects of curiosity and entertainment and often handled and passed around from one human to another.

Many jurisdictions allow MLAPs to operate because of their purported educational value $[3,4,5,6]$. MLAPs claim to be providing a service to the public, not only by providing entertainment, comfort or joy to humans, but also by providing education in the form of factual knowledge about animals and their habitats, as well as knowledge about conservation $[3,4,5,6]$. On their company website, Hands on Exotics, for example, states "meeting and interacting with our animal ambassadors in person not only helps to enhance learning, but helps to promote a positive relationship between both humans and animals," (2017 -05-18). Some MLAPs, furthermore, purport to help in broader conservation efforts by instilling in the public an interest in conservation through their live animal presentations. On their website, Animal Wonders, for example, states "the final 
objective of Animal Wonders is to support and promote conservation efforts locally, nationally, and internationally" (2017-05-18).

Given these educational claims as the basis for allowing MLAPs to continue, it is essential to examine whether they are valid. Thus, the aim of this paper is 1) to determine how and if learning can empirically be measured in the context of MLAPs, and 2) to critically examine whether the educational claims are valid. This analysis will assist in addressing the question of whether MLAPs warrant special consideration when it comes to laws restricting or prohibiting animal use within municipal or provincial/state boundaries.

\section{What is education?}

In order to determine if there is inherent educational value in MLAPs, it is therefore necessary to consider what education is, how it is measured, and to address positive versus negative educational value. To do so, the present assessment will use the term educational value to encompass learning that is either cognitive and/or affective. In this context, cognitive learning pertains to the gaining of facts and knowledge regarding animals and their habitats - that is, education as purely increased knowledge or understanding about animals, their behaviour, and habitats [7,8]. Affective learning pertains to, often emotion-driven attitude change towards wildlife and conservation - that is education that motivates increased concern about issues of conservation $[7,8]$. Affective learning also refers to behavioural change - education that leads to attitude change resulting in real world change/helping conservation efforts with action [8].

Education, or learning, also may have a valence. Positive learning refers to learning that leads to the acquisition of accurate knowledge about species, their natural habitats and conservation issues, as well as positive behavior. Negative learning refers to inaccurate information about species, their natural habitats and conservation issues as well as negative perceptions about species, conservation action, and/or the normalizing of captivity $[9,10]$.

\section{Education and standard zoos.}

It may be instructive to assess questions about the educational value of MLAPs in a comparative context with standard modern zoos (acknowledging that modern zoos run the gamut in terms of quality and experiences for both the animals and the visitors). Research on learning (informal learning) in standard zoos and aquariums has assessed cognitive learning, that is the retention of specific facts regarding species, their behaviour and conservation, and also affective learning, that is, learning that results in attitude change or behavior benefitting conservation of animals. This paper, however, is not intended as an exhaustive analysis of the educational claims of standard zoos.

While research on learning in traditional zoos and aquariums has pointed primarily to short term cognitive learning, i.e., the retention of particular facts regarding species, their behavior and conservation, evidence of long term cognitive knowledge gained is scant [11,12]. Even more scant is evidence of affective learning, i.e., learning that results in an attitudinal change or behavioral change in terms of conservation efforts [13]. One-day zoo visits have little long-term impact on cognitive and affective learning [12]. While a desire to help conservation action has been shown to increase 
immediately after zoo visits, this desire does not persist over time or result in real-world action [11]. Follow-up interventions are necessary to impact long-term knowledge gained and behavioural change $[12,13,11]$.

When short term learning does occur in standard zoos it is correlated with the following criteria:

- Naturalistic free-range exhibits: viewing animals in surroundings that more closely emulate their natural habitats allow for observation of a greater range of semi-naturalistic behaviors. Some studies have correlated such displays with visitor learning, as they increase interest in and empathy for the animals, however, these studies have concluded that naturalistic displays have been shown to have only a cognitive learning impact on zoo visitors [14,15]. Furthermore, these studies did not involve follow up and therefore could not determine if learning was long term. Learning in this situation was limited to guided exhibits in which visitors received structured information about the animals on exhibit [14,15].

- Enrichment presentations: training sessions allow for animal activity which results in increased visitor interest in the animal being viewed as well as an increase in stay time at an exhibit. These two factors (naturalistic exhibits and enrichment presentations) have been correlated with promoting conditions for learning in humans and increased positive perceptions of the animals viewed [14].

In terms of other elements of standard zoo exhibits, most research has concluded that the use of sign displays and interactive graphics are among the least effective methods of education in a zoo setting [16]. or only minimally interesting, and therefore minimally helpful to zoo visitors' increased knowledge regarding species, their habitats, and conservation issues $[17,18]$. On the other hand, some studies have provided evidence that these tools are useful for increased cognitive learning [19,20,14].

In summary, the evidence for short-term cognitive or affective learning in modern zoos is modest at best, but there is little to no support for long term learning of any kind. Moreover, studies of informal learning in zoos do not assess negative learning, that is, the adoption of inaccurate information about the animals or anti-conservation attitudes, and there is evidence to support this premise that negative learning occurs [21,22]. Ross et al. 2008 found that chimpanzees were less likely to be viewed as endangered compared to gorillas and orangutans due to their high visual presence in the media and advertisements. A 2015 study found that when viewing images of chimpanzees in either a naturalistic or anthropomorphic setting, with a human present or absent, they were perceived to be more stable in their wild populations as well as more desirable as pets [21]. These findings can be extrapolated to apply to zoo exhibits that display endangered or unstable populations. In other words, viewing wild animals in anthropomorphic settings, which include presentation with humans, has a negative impact on cognitive or affective learning.

\section{Education and MLAPs.}

None of the criteria that are presumed to most effectively allow for positive cognitive learning in zoos - naturalistic exhibits allowing semi-natural behaviors, environmental enrichment presentations, signs or interactive graphics, and reinforcement - are possible with MLAPs. Therefore, the question is whether there is evidence of any positive learning in MLAPs and, likewise, whether there is the potential for negative learning. 


\section{Positive Learning:}

Attention has long been considered a necessary precursor to positive cognitive learning [19,23]. In the zoo context, visitors' attention has been presumed to be captured most successfully by naturalistic designs, by observing active animals - which such designs and environmental enrichment can elicit - signage and/or graphics, and reinforcement [19].

- Naturalistic free-range exhibits: The animals that are used in MLAPs are not exhibited in naturalistic displays but are, rather, displayed out of their natural environments [24,25]. Even nocturnal animals, such as hedgehogs, are used during daytime displays $[4,5,6]$. The animals are not allowed to free-range, but are contained until they are displayed, with smaller species often constrained to a handler's grip, or kept in small containers [26,27]. For these reasons, the animals are prevented from displaying any range of behaviours, let alone naturalistic ones [28,29,30].

- Environmental enrichment: The animals that are used in MLAPs are not generally given environmental enrichment activities that in zoos, serve to help elicit species-specific natural behaviours and prevent stereotypies. Such enrichment includes, for example, the introduction of objects to manipulate, enhancing habitat, presenting food in a variety of ways, allowing for interspecies or conspecies interactions and sensory stimulation - all of which help to elicit behaviours that would be naturalistic in the wild [19]. Their environmental constraints - being confined and/or kept in small containers - do not allow for the environmental stimuli needed for physiological and psychological wellness.

- Signage/graphics: While some MLAPs do present signage/graphics, these displays are almost always minimal, and often inaccurate [3,31].

- Reinforcement: Unlike conventional zoos that visitors often visit on multiple occasions, MLAP's are usually one-time presentations, therefore the opportunity for reinforcement, including reinforcement of a conservation message, does not exist as these programs provide no follow-up interventions.

MLAPs are at a further disadvantage for providing positive cognitive and/or affective learning opportunities in comparison to well-run progressive modern day zoos for several other reasons. In terms of cognitive learning of animal facts, it may be that live animals actually serve as a distraction rather than a learning tool in this context. While there is currently a lack of research in this area, some observations suggest that as the number of animals used increases, the chances of children being distracted also seems to increase [32, personal communication, Rob Laidlaw, Zoocheck, 2017-04-24]. While participants at MLAPs presentations are often encouraged to be quiet, these programs can be very loud and chaotic when animals are brought out [personal communication, Rob Laidlaw, Zoocheck, 2017-04-24].

For-profit and program success goals often conflict with education goals of MLAPs. MLAPs that are privately owned and operated, as well as those that are non-profit, often measure program success by factors such as financial gain, or number of presentations conducted. These goals are prioritized above positive learning goals and result in cognitive learning that, if it does occur, is based on characteristics of the animals that are irrelevant to their conservation. An example of this is how animals that typically get the most positive and enthusiastic reactions from participants are prioritized for display, so that furry, colourful, active and large animals are more frequently learned 
about, creating a bias in the cognitive learning component [33,34]. The display is driven by what is popular, rather than by a coherent educational purpose. ${ }^{1}$

MLAPs typically have no discernable conservation action plan. The lack of a conservation action plan or petition at these exhibits and presentations results in them being extremely unlikely to produce any kind of measurable affective learning outcome. Behavioural change that results in real-world action is most likely to occur right after exposure to information [32]. The most prominent zoo accreditation organizations including the World Association of Zoos and Aquariums, the American Association of Zoos and Aquariums, the Canadian Association of Zoos and Aquariums, the Zoological Association of America and the European Association of Zoos and Aquaria all concur that education, rather than being merely inspirational or emotive, should have an 'action' component that allows for positive conservation action [33]. Furthermore, since MLAPs do not have a follow-up process to these one-time experiences for participants, affective learning is unlikely to translate into positive conservation action, or if it does, there is no current evidence for it.

\section{Negative Learning:}

In addition to these obstacles to positive learning, negative learning can take place during MLAPs in a wide variety of ways. As these exhibits and presentations are often small operations not run by by individuals with expertise in animal behavior and welfare, the animal "facts" they present can be outdated or simply incorrect. Furthermore, the animals presented are in many ways not representative of their wild counterparts as they are entirely removed from their natural ecological contexts, thus extrapolating information about animal "ambassadors" to the species at hand in general is often inaccurate. Further negative learning aspects include the following:

- Some MLAPs use animals as Play objects, such as when they place frogs on children's heads or wrap snakes over a participant's shoulder or around a child's waist $[35,36]$. These kinds of actions, rather than introducing in children love and respect for other animals [37] reinforces the notion that they are objects to be used for entertainment. This, as Donaldson and Kymlicka state, inculcates children into an ideology of species superiority and entitlement [37].

- Participants of MLAPs are more likely to respond to wild animals as domesticated. Research has shown that participants who view wild animals in an anthropomorphic setting while in contact with humans are more likely to respond to the animals presented on a personal level, and as less threatening [21]. They often want to know facts such as the age or name of the exhibited animal, and how many babies the animal has had. This personalization of individual exotic animals has a domesticizing and false familiarity effect which can lead to the confusion of wild and domesticated species, underscoring the idea that exotic species are like pets or are pets $[38,21]$. This fact can be extrapolated to the desire to own an exotic animal, which can promote the exotic pet trade.

- Importantly, the biology and conservation status of animals used in MLAPs may be inaccurately perceived by the public as the result of such programs [21,22]. As an example, as with the case of primates in the Ross et al. (2008) study, animal "ambassadorship" - the viewing of animals in an anthropomorphic setting and/or in the presence of humans - may lead to the lessoning of concerns about the status of their wild counterparts. That is, these situations promote the false impression that the species being viewed is readily available and in abundance [21]. 
- Seeing animals in captivity normalizes captivity. One recent study that asked different groups of schoolchildren where they would go to find out about nature after viewing animals in one of three different informal settings - at a museum, at a live animal show, and at a natural outdoor environment center - found that the children who had viewed animals in nature were more likely to write or draw animals in parks while the children who had viewed animals at a live animal show were more likely to write or draw zoos [38].

\section{Conclusions}

There is no substantive evidence to support the purported claims that Mobile Live Animal Programs are educationally beneficial. As with traditional zoos, there is a distinct problem with the over-exaggeration of claims of educational impact in MLAPs without supporting evidence of measurable outcomes. Furthermore, these unsubstantiated claims of positive educational value are in turn used by MLAPs as a major justification for their existence, allegedly compensating for safety and welfare concerns. In addition, learning outcomes of MLAPs may even be negative for a variety of reasons. One indisputable negative learning outcome from the use of animals in MLAPs is that participants witness animals' lack of natural environment, freedom and privacy; an experience that normalizes assumptions about human dominance and the utilization and exploitation of animals.

When it comes to an assessment of whether or not MLAPs should be allowed to operate, concern should be given to the pervasive problem of using animals in the name of education and conservation. Making large unsubstantiated claims about positive educational value is educationally irresponsible. It negatively impacts the public's perception - and perhaps most crucially, children's perception, about other species and the environment. It is of great importance to weigh the acquisition of cognitive facts about animals, their behaviour and conservation with the acquisition of information that may be inaccurate or that contributes to a psychological mindset that can be deemed negative education. Learning that leads to an attitude of unnecessary human use of animals, and the systemic objectification and exploitation of them is miseducation.

It is not recommended, therefore, based on their purported educational claims, that MLAPs be given special consideration when it comes to laws restricting or prohibiting animal use within municipal or provincial/state boundaries.

Acknowledgments: I thank Zoocheck Inc. for funding and logistical support.

Conflicts of Interest: Kathryn Sussman is an independent consultant for Zoocheck Inc. and The Whale Sanctuary Project. Zoocheck Inc. provided KS with funding and logistical support for research but had no part in the research, analysis, interpretation and conclusions presented, which remain those of the author.

\section{References}

1. Ballantyne, R.; Packer, J.; Hughes, K.; Dierking, L. Conservation learning in wildlife tourism settings: lessons from research in zoos and aquariums. Environmental Education Research 2007, 13(3), 367-383.

2. Rothfels, N. Savages and Beasts: The Birth of the Modern Zoo, Baltimore: Johns Hopkins UP: Baltimore, U.S.A, 2002.

3. [Animal Wonders Montana]. (2015, July 9). Bringing the Zoo to You! Retrieved from 
https://www.youtube.com/watch?v=nqVtF-VQHSs.

4. Hands On Exotics (2017, March 26). Retrieved from http://www.handsonexotics.com/animals.

5. Travelling Critters (2017, March 26). Retrieved from http://travellingcritters.com/animals/.

6. Zoo To You (2017, March 26.) Retrieved from http://www.zootoyou.ca/ontario-mixture-exotic-animals-displays-exhibits.

7. Briseno-Garzon, A.; Anderson, D.; Anderson, A. Adult learning experiences from an aquarium visit: the role of social interactions in family groups. Curator 2007, 50(3), 299-318.

8. Broad, S.; Weiler, B. Captive animals and interpretation - a tale of two tiger exhibits. The Journal of Tourism Studies 1998, 9(1), 14-27.

9. Jamieson, D. Against zoos. In defence of animals, P. Singer Ed., Basil Blackwell, New York, U.S.A., 1985; pp. 108-117.

10. Wagoner, B.; Jenson, E. Science learning at the zoo: evaluating children's developing understanding of animals and their habitats. Psychology and Society 2010, 3(1), 65-76.

11. Smith, L.; Broad, S.; Weiler, B. A closer examination of the impact of zoo visits on visitor behaviour. Journal of Sustainable Tourism 2008, 16(5), 544-562.

12. Adelman, L. M.; Falk, J. H.; James, S. Impact of national aquarium in Baltimore on visitors' conservation attitudes, behavior, and knowledge. Curator 2000, 43(1), 33-61.

13. Marino, L.; Bradshaw, G.; Malamud, R. The captivity industry: the reality of zoos and aquariums. Best Friends Magazine, 2009, March/April, 25-27.

14. Fernandez, E. J.; Tamborski, M. A.; Pickens, S. R.; Timberlake, W. Animalvisitor interactions in the modern zoo: conflicts and interventions. Applied Animal Behaviour Science 2009, 120, 1-8.

15. Reade, L. S.; Waran, N. K. The modern zoo: how do people perceive zoo animals? Applied Animal Behaviour Science 1996, 47, 109-118.

16. Simpkin, L. Interpretation - starting with the tourist. Interpretation attached to heritage. Papers presented at the Third Annual Conference of Interpretation Australia Association Inc. $5^{\text {th }}-7^{\text {th }}$ December 1994. Albury: Charles Sturt University, 184-188.

17. Kellert, S. R.; Berry, J. K. Knowledge Affection and Basic Attitudes Toward Animals in American Society: Phase III. US Government Printing Office, Washington, DC, U.S.A., 1980.

18. Uozumi, A. "Do Zoos Work at Raising Awareness? Quantifying the Impact of Informal Education on Adults Visiting Japanese Zoos.” MS thesis Imperial College London, 2010.

19. Altman, J.D. Animal activity and visitor learning at the zoo. Anthrozoos 1998, 11(1), 12-21.

20. Ballantyne, R. Young students' conceptions of the marine environment and their role in the development of aquaria exhibits. Geojournal 2004, 60, 159-163.

21. Leighty, K.; Valuska, A.J.; Grand, A.P.; Bettinger, T.L.; Mellen, J.D.; Ross, S.R.; Boyle,

P.; Ogden, J.J. Impact of visual context on public perceptions of non-human primate performers. PLoS One 2015, 10(2), 1-6.

22. Ross, S.R.; Lukas, K.E.; Lonsdorf, E.V.; Stoinski, T.S.; Hare, B.; Shumaker, R.; et al. Inappropriate use and portrayal of chimpanzees. Science 2008, 319: 1487. 
23. Ashcroft, M.H. Human Memory and Cognition $2^{\text {nd }}$ ed.; Harper Collins College Publishers, New York, U.S.A., 1994.

24. [Casswastaken]. (2015, July 15). Wild Animals in My Backyard. Retrieved from https://www.youtube.com/watch?v=ZzfDCgYLAXs.

25. [Kitty Pouncer]. (2011, October 19). Animals Visit Nursing Home. Retrieved from https://www.youtube.com/watch?v=-jhpJaGk2yM.

26. [Breakfast Television]. (2016, October 5). Hands on Exotics at PumpkinFest. Retrieved from https://www.youtube.com/watch?v=Ui0d1rSY-sA\&t=260s.

27. [CNN]. (2012, November 26). Jack Hanna, Piers Morgan, and a Cheetah. Retrieved from https://www.youtube.com/watch?v=_HWVNlr4YI.

28. Coe, J.C. Design and perception: making the zoo experience real. Zoo Biology 1985, 4, 197-208.

29. Hancocks, D. Bringing nature into the zoo: inexpensive solutions for zoo environments. International Journal for the Study of Animal Problems 1980, 1(3), 170-177.

30. Hutchins, M.; Hancocks, D.; Crocket, C. Naturalistic solutions to the behavioural problem problems of captive animals. Annual AAZPA Conference Proceedings, Wheeling West Virginia. 1979, pp. 108-113.

31. [Creeping Things]. (2017, March 18). Creeping Things Live Animal Shows. Retrieved from https://www.youtube.com/watch?v=7_zGvZIRTFk.

32. Smith, L.; Weiler, B.; Ham, S. The rhetoric versus the reality: a critical examination of the zoo proposition. Zoos and Tourism: Conservation, Education, Entertainment? Ed. Frost, W., Channel View Publications, Toronto, Canada, 2011; pp. 59-68.

33. Moss, A.; Esson, M. The educational claims of zoos: where do we go from here?

Zoo Biology 2013, 32, 13-18.

34. Roe, K.; McConney, A. Do zoo visitors come to learn? An internationally comparative, mixed-methods study. Environmental Education Research 2015, 21(6), 865-884.

35. [Family Fun Pack]. (2016, May 17). David's Awesome Amazing Reptile Birthday Party.

Retrieved from https://www.youtube.com/watch? $=$ GgiBBmpJXmE.

36. [Party Pop]. (2016, April 7). Mobile Zoo of Southern California - Animals for Parties

Riverside and Los Angeles area CA. Retrieved from https://www.youtube.com/watch?v=oQ-1Y-Hn1fM.

37. Donaldson, S.; Kymlicka, W. Zoos and circuses: the wrong kind of education about animals. The Globe and Mail 6 May. 2016, early ed.

38. Kimble, G. Children learning about biodiversity at an environment centre, a museum and at live animal shows. Studies in Educational Evaluation 2014, 41, 48-57. 